\title{
Consumo frecuente de alimentos industrializados y su percepción en adolescentes indígenas Mayas con sobrepeso y obesidad
}

\author{
Frequent consumption of industrialized food and its perception \\ among overweight and obese indigenous Mayan adolescents
}

Odette Pérez-Izquierdo (https://orcid.org/0000-0002-4145-1639) ${ }^{1}$ Sergio Cárdenas-García (https://orcid.org/0000-0002-2734-4220) ${ }^{1}$ Irma Aranda-González (https://orcid.org/0000-0001-7700-8666) ${ }^{1}$ Javier Perera-Ríos (https://orcid.org/0000-0001-8779-7160) ${ }^{1}$ María del Rosario Barradas Castillo (https://orcid.org/0000-0002-6088-9505) ${ }^{1}$
${ }^{1}$ Facultad de Medicina, Universidad Autónoma de Yucatán. Av. Itzaes\#498 por 59 y 59a Centro. 97000 Mérida Yucatán México. odette.perez@ correo.uady.mx

\begin{abstract}
The scope of this paper was to identify what kind and which type of modern industrialized foods that overweight and obese adolescents consume and the perception they have of them. The study was of the qualitative-quantitative, descriptive and interpretative type and was conducted with adolescent students from four high schools in the municipality of Abalá, Yucatán, Mexico. It consisted of three stages, the first of which involved recording anthropometric measurements of 292 high school students to obtain their Body Mass Index. In the second stage, 58 students who were overweight and obese were randomly selected and a food consumption frequency questionnaire was applied. In the third stage, four focus groups were held to ascertain the perception with respect to food consumption. A high intake of modern industrialized foods was observed at breakfast, school break and dinner, though traditional dishes are still consumed at mealtimes. The conclusion drawn is that there is a transculturation of food among adolescents.
\end{abstract}

Key words Industrialized foods, Overweight, Obesity, Adolescents, Indigenous people
Resumen Se planteó como objetivo identificar cuáles y de qué tipo son los alimentos industrializados modernos que los adolescentes con sobrepeso $y$ obesidad consumen y la percepción que tienen de ellos. El estudio fue de tipo cuali-cuantitativo, descriptivo e interpretativo; se llevó a cabo con estudiantes adolescentes de cuatro secundarias del municipio de Abalá, Yucatán, México. Constó de tres etapas, en la primera se realizaron mediciones antropométricas a 292 estudiantes de las secundarias para obtener el Índice de Masa Corporal, en la segunda se seleccionaron al azar 58 estudiantes que presentaron sobrepeso y obesidad; a los cuales se les aplicó un cuestionario de frecuencia de consumo de alimentos. En la tercera etapa se realizaron cuatro grupos focales para conocer la percepción respecto al consumo de alimentos. Se observó una ingesta alta de alimentos industrializados modernos en el desayuno, receso escolar y cena; en el tiempo de la comida aún se consumen preparaciones tradicionales. Existe una transculturación de la alimentación en los adolescentes.

Palabras clave Alimentos industrializados, Sobrepeso, Obesidad, Adolescentes, indígenas 


\section{Introducción}

La alimentación involucra procesos biológicos y fisiológicos esenciales, pero no solo consiste en el mero acto de comer, sino que en él intervienen otros factores indispensables como la cultura ${ }^{1}$, los procesos sociales, psicológicos, económicos, simbólicos, religiosos, entre otros ${ }^{2}$. En este sentido, la selección de alimentos y la satisfacción de estos se enmarcan dentro de una gama de posibilidades que van entre comer como se debe, como se quiere y como se podría comer, debido a que la alimentación juega una función social importante ${ }^{3}$.

Dentro de este contexto alimentario, los adolescentes tienen una forma peculiar de llevarla a cabo, debido a diversos procesos propios de la edad, ya que es el tránsito de la niñez a la etapa adulta, donde enfrentan cambios biopsicosociales $^{4}$ con el fin de buscar su propia identidad, su autonomía y dejando de lado la influencia familiar $^{5}$. Los jóvenes buscan pertenecer a un grupo social e identificarse con las costumbres y la moda de su generación, siendo la alimentación un eje importante de la participación y convivio entre ellos, eligiendo alimentos industrializados con alto contenido calórico ricos en hidratos de carbono, grasas, sal y pobres en nutrimentos en lugar de una alimentación saludable ${ }^{6}$.

En la actualidad, la modernización de la dieta ha afectado a todos los grupos sociales debido a los cambios alimentarios que han sido impulsados por una economía capitalista y globalizante ${ }^{7}$, situación de la que desafortunadamente no ha escapado el medio rural y las comunidades indígenas pobres debido al mayor acceso, disponibilidad -principalmente de escolares y adolescentes- a productos industrializados que conlleva a cambios en los estilos y hábitos de consumo eligiendo una "dieta occidental", debido a su bajo costo. Estas nuevas condiciones de alimentación han cambiado sustancialmente la dieta tradicional, ya que de productos considerados como la base de la dieta (chile, frijol, maíz, huevo, tortilla, algunas verduras y bebidas como pozol y atole) en las comunidades rurales e indígenas, se empezaron a consumir alimentos industrializados, baratos y de alta densidad energética ${ }^{9,10}$; lo que ha llevado a la población juvenil indígena a enfrentar la doble carga de malnutrición, es decir, tanto, desnutrición como sobrepeso y obesidad ${ }^{11}$.

México ha sufrido una transición alimentaria profunda, que ha tenido implicaciones severas en la salud de la población llevándola a una transición epidemiológica ${ }^{12}$. Esto ha ocasionado que las tasas de sobrepeso y obesidad sean muy preocupantes debido a su incremento, la balanza se ha inclinado a un mayor porcentaje de población que presenta esta condición en el medio rural, es decir, aquellas con menor poder adquisitivo ${ }^{13}$.

En 2012, la Encuesta Nacional de Salud y Nutrición, reportó que la prevalencia nacional combinada de sobrepeso y obesidad en adolescentes fue alrededor de $35.8 \%$ para el sexo femenino y $34.1 \%$ en el sexo masculino. En este mismo sentido, UNICEF ${ }^{11}$ reporta que 1 de cada 3 niños y niñas de 6 a 11 años presentan sobrepeso y obesidad, esta situación se duplica alarmantemente en población adolescente, siendo más acentuada en aquellas de comunidades rurales e indígenas. Para los adolescentes de Yucatán en localidades urbanas, la cifra de sobrepeso más obesidad pasó de $43.5 \%$ en 2006 a $42.0 \%$ en 2012 . Y para las de localidades rurales esta cifra representa (actualmente) el 52.0\%, lo que señala un importante aumento de la combinación del sobrepeso y obesidad. Debido a esto, se ha observado un aumento drástico en enfermedades como diabetes, riesgo cardiovascular, entre otras, en población joven ${ }^{14}$.

En la actualidad, el área biomédica, entre ellos, los nutricionistas impulsan la promoción de una alimentación saludable en la población ${ }^{15}$ específicamente, en los escolares y adolescentes, ya que se han convertido en un grupo de riesgo debido al alto porcentaje de sobrepeso y obesidad que presentan ${ }^{14}$. La dieta es un determinante fundamental para una buena o mala nutrición de los individuos, por ello la importancia de analizarla no solo desde una visión biológica, sino también sociocultural $^{16}$, ya que las personas seleccionan los alimentos no solo para nutrirse, sino porque tiene diversos significados simbólicos y materiales, por ello, la importancia de emplear una visión diferente a la biomédica.

Una temática esencial para el estudio de la alimentación es la percepción que las personas tienen de ella, debido a que forma parte de las representaciones mentales de lo captado por los sentidos, las ideas, los conocimientos y las sensaciones internas ${ }^{17}$. Vargas ${ }^{18}$ comenta que las percepciones son los procesos cognitivos que consiste en el reconocimiento, interpretación y significados para la elaboración de juicios en torno a las sensaciones obtenidas del ambiente físico y social, en el que intervienen procesos de la psique entre los que se encuentran el aprendizaje, la memoria y la simbolización.

En este sentido, los adolescentes tienen sus propias maneras de comer y actitudes hacia los alimentos, que pueden variar de acuerdo al en- 
torno en el que se encuentran manifestando significados, utilidades o razones para comerlos o no ${ }^{19}$.

Estudiar las percepciones de los adolescentes de comunidades rurales e indígenas no ha sido el eje central de los estudios desde la perspectiva biomédica, esta fue la motivación para realizar la investigación que tuvo como objetivo conocer cuáles son los alimentos que consumen frecuentemente, por qué los consumen, cuáles son los alimentos que comen en casa y con sus amigos, cuáles prefieren comer y por qué.

\section{Metodología}

La investigación se llevó a cabo en el municipio de Abalá, Yucatán, situado en la zona norponiente del estado y se caracteriza por pertenecer a la región ex henequenera. Está conformada por 8 localidades y tiene una población aproximada de 6,502 habitantes (de los cuales $18.6 \%$ son adolescentes), el 51\% habla lengua maya ${ }^{20}$; y entre el 40 y el $60 \%$ se encuentra en situación de pobreza y pobreza extrema ${ }^{21}$. La población está inmersa en un entorno adverso al del bienestar y de desarrollo social, presentando un rezago medio ${ }^{22}$. En cuanto a la situación de pobreza, UNICEF ${ }^{11}$ reporta que a nivel nacional el 78.2\% de los y las adolescentes indígenas viven en condiciones de pobreza, desafortunadamente no se cuenta con el dato de adolescentes indígenas yucatecos en esta situación.

El estudio es de tipo mixto cuali-cuantitativo, descriptivo e interpretativo. La investigación consistió en tres etapas. Las primeras dos cuantitativas y la tercera cualitativa. Se trabajó con un total de 292 adolescentes escolarizados entre 12 y 17 años de edad, inscritos en las 4 secundarias del municipio. Las escuelas se encuentran ubicadas en las localidades de Uayalceh, Mucuyché, Temozón Sur y la cabecera municipal Abalá.

Para la participación de los adolescentes, se solicitó autorización a los padres de familia a través de la firma del consentimiento informado y a los estudiantes a través del asentimento informado para realizar cada una de las actividades con ellos. Se les explicó a detalle en qué consistía el estudio y los objetivos de este.

En la primera etapa, a todos los estudiantes de las escuelas (292), se les realizaron medidas antropométricas (peso y talla) para identificar el Índice de Masa Corporal (IMC). La clasificación del IMC, se tomó como referencia los puntos de corte establecidos por la Organización Mundial de la Salud (OMS) ${ }^{23}$, de acuerdo a los percentiles, los cuales consideran los siguientes parámetros: obesidad, $>95$; sobrepeso, $>85$ a $<95$; normopeso, $>3.1<85$ y delgadez $<3$.

Posteriormente, en la segunda etapa se realizó un muestro probabilístico (por las limitaciones del estudio) para identificar de manera representativa, aquellos alimentos industrializados e industrializados modernos (Cuadro 1) que son consumidos con frecuencia por los adolescentes diagnosticados en la primera etapa con sobrepeso y obesidad. La fórmula para el cálculo de la "n" se presenta a continuación:

$$
\mathrm{n}=\mathrm{n}_{0} /\left(1+\mathrm{n}_{0} / \mathrm{N}\right) .
$$

Dónde: $\mathrm{n}_{0}=\left(\mathrm{p}^{\star} \mathrm{q}^{\star} \mathrm{z}^{2}\right) / \mathrm{d}^{2}$

Los resultados de la frecuencia de consumo de alimentos se clasificó de acuerdo al Sistema Mexicano de Alimentación ${ }^{24}$, obteniéndose cuatro grupos: 1) cereales sin grasa, 2) cereales con grasa), 3) aceites y grasas; y 4) azúcares con y sin grasa. La frecuencia de consumo de alimentos se interpretó de acuerdo a la clasificación utilizada por Franco y Valdéz ${ }^{25}$ : consumo alto: de tres veces o más días a la semana, consumo moderado: dos veces por semana, consumo bajo una vez a la semana; y no consumo: cuando el alimento no se consume.

Finalmente, la tercera etapa se centró en el estudio de la percepción del consumo de alimentos industrializados. Para ello se realizaron 5 grupos focales en tres escuelas: Abalá (3), Uayalceh (1) y Temozón Sur (1), en la secundaria de Mucuyché no se realizó la técnica debido a que el número de participantes era reducido. Los grupos estuvieron integrados de ocho a doce adolescentes con diagnóstico de sobrepeso y obesidad, seleccionados al azar. Esta técnica se realizó con el propósito de explorar los conocimientos, experiencias, actitudes y creencias sobre alimentos consumidos y la razón de ello, dando mayor énfasis a los alimentos industrializados buscando un ambiente de interacción y respeto, lo que permitió una conversación abierta, participativa, donde se conjugó el preguntar dudas y platicar experiencias. Las categorías estudiadas fueron: tiempos de comida, motivos de su consumo, gustos y preferencias, alimentos que consumen cuando están reunidos con sus amigos, y finalmente, alimentos industrializados "buenos o malos". Las sesiones fueron grabadas, transcritas, revisadas y categorizadas, codificadas y finalmente analizadas. Para el análisis de los resultados se empleó la saturación teórica ${ }^{26}$. 
Cuadro 1. Glosario de términos.

\begin{tabular}{|c|c|}
\hline Término & \\
\hline $\begin{array}{l}\text { Alimento } \\
\text { industrializado }\end{array}$ & $\begin{array}{l}\text { Son aquellos procesados por industrias alimentarias centralizadas, con altos volúmenes de } \\
\text { producción y distribución regional o nacional. Por lo general son de fácil acceso y se presentan } \\
\text { como congelados, listos para procesar, cocinar, calentar o consumirse. }\end{array}$ \\
\hline $\begin{array}{l}\text { Alimento } \\
\text { industrializado } \\
\text { moderno }\end{array}$ & $\begin{array}{l}\text { Estos alimentos pueden encontrarse en un solo alimento o una forma de una mezclas } \\
\text { invisibles, por ejemplo, por ejemplo, leches modificados en su composición (en polvo, } \\
\text { descremadas, semidescremadas, entre otros), cereales para el desayuno, pan integral, pan de } \\
\text { trigo salado, embutidos, pan dulce empacado, aceites y grasas modificadas, azúcares líquidas o } \\
\text { sólidas, refrescos productos de bebés y complementos alimenticios. }\end{array}$ \\
\hline Percepción & $\begin{array}{l}\text { El término percepción es usado en el mundo hispanoamericano tanto para señalar la } \\
\text { representación mental de lo captado por los sentidos, para indicar ideas, conocimientos } \\
\text { y sensaciones internas. Se pueden hablar de percepción toda vez que la sensualidad, la } \\
\text { emotividad y el conocimiento no quedan confinados en el individuo, sino que se establecen } \\
\text { afinidades y divergencias a niel familiar, étnico, territorial, etc., surgiendo tipicidades } \\
\text { claramente observables tanto a nivel de la sensibilidad como del discurso social, evidenciando } \\
\text { a la comida como un hecho cultural de múltiples significaciones. Al indagar sobre la } \\
\text { percepción son las nociones populares, las creencias, expectativas, estereotipos, temores y } \\
\text { fervores de los consumidores de alimentos. }\end{array}$ \\
\hline Chicharra & $\begin{array}{l}\text { Chicharra deriva de la voz onomtopéyica chicharrar: “freir, cocer, asar, o tostar un alimento } \\
\text { hasta que tome sabor a quemado". La acepción que se tienen en Yucatán es “carne o cuerpo } \\
\text { con grasa de cerdo sin pelo, que se fríe en su propia grasa agregando sólo sal”. Se usa en } \\
\text { femenino chicharra en tanto que en otras regiones de México se le llama chicharrón. La } \\
\text { elaboración de la chicharra en Yucatán desde siempre ha estado íntimamente unidad la } \\
\text { matanza de cerdo; es botana de bar o cantina, comida casera o fiestera; regularmente incluye } \\
\text { la "cáscara" o cuero frito de cerdo; el p'uyul (participio pasivo del verbo maya p'u’uy más-ul, } \\
\text { palabra maya que significa "quebrar o desmoronar cosas secas"). }\end{array}$ \\
\hline Tortilla & $\begin{array}{l}\text { Alimento que forma parte de la alimentación diaria de los mexicanos, desde la época } \\
\text { prehispánica. Consiste en una preparación de forma circular y plano que se hace con masa } \\
\text { de maíz o hecha a mano, que se cocina al fuego y se come sola o con diversas preparaciones, } \\
\text { constituye un elemento esencial en la alimentación mexicana. }\end{array}$ \\
\hline Burritas & $\begin{array}{l}\text { Las burritas en la comunidad consisten en una preparación con tortilla de harina, untada con } \\
\text { mayonesa acompañado de jamón (puede ser de cerdo o de pavo) aunque regularmente es de } \\
\text { cerdo de mala calidad por bajo costo, algunas veces puede ir acompañado de queso de hebra. }\end{array}$ \\
\hline Salbutes & $\begin{array}{l}\text { Es un antojito que forma parte de la cocina tradicionales yucateca, el cual consiste en una } \\
\text { tortilla que se hace a mano, se sofríe, va acompañado en la parte de arriba de una hoja de } \\
\text { lechuga, tomate en rodajas, rebanadas de aguacate, cebolla morada, carne deshebrada, que } \\
\text { puede ser de pollo, pavo o cochinita pibil y finalmente, con salsa de chile habanero. }\end{array}$ \\
\hline Puchero & $\begin{array}{l}\text { Es un platillo de la gastronomía yucateca tradicional, basado en tres carnes (res, cerdo y } \\
\text { pollo), en compañía de algunas verduras como calabaza, zanahoria, papas, repollo, tomate, } \\
\text { chayote }\end{array}$ \\
\hline Cochinita pibil & $\begin{array}{l}\text { Es un platillo de la gastronomía yucateca tradicional, basado en carne de cerdo adobada en } \\
\text { achiote, envuelta en hoja de plátano y cocida dentro de un horno de tierra. La cochinita pibil } \\
\text { se acompaña con cebolla morada en naranja agria Generalmente en tortas y tacos con un } \\
\text { encurtido de chile habanero muy común en la región }\end{array}$ \\
\hline
\end{tabular}

\section{Análisis estadístico}

El análisis de los resultados respecto a la frecuencia de consumo de alimentos en la población de estudio fue de tipo descriptivo a través de tablas de frecuencia, las cuales fueron divididas por sexo y comunidad, con la finalidad de observar el comportamiento en la ingesta de estos alimentos en ambas clasificaciones. Dicho análisis fue a través del paquete estadístico Stata 11.0, cabe mencionar que debido al número de datos obtenidos en la comunidad de Mucuyché y la falta de observaciones, en la clasificación de cada alimento, no permitió realizar el estadístico comparativo en 
Cuadro 1. Glosario de términos.

\begin{tabular}{|c|c|}
\hline Término & \\
\hline Panuchos & $\begin{array}{l}\text { Los panuchos son un platillo de la cocina de la Península de Yucatán. Son pequeños tortillas } \\
\text { de maíz fritas hechas a mano, a las que se les hace un corte por el que se mete un guiso hecha } \\
\text { a base de frijol y que luego son fritas en aceite o manteca de cerdo. Posteriormente se adorna } \\
\text { con hojas de lechuga, carne de pavo guisado, tomate y cebolla previamente sazonados con } \\
\text { naranja agria y sal, aguacate, zanahoria y recado colorado (achiote). Se pueden acompañar } \\
\text { con una cantidad extra de salsa picante hecha a base de chile habanero. }\end{array}$ \\
\hline Tamales & $\begin{array}{l}\text { El tamal (del náhuatl tamalli, que significa envuelto) es un nombre genérico dado a varios } \\
\text { platos americanos de origen indígena preparado generalmente con masa de maíz cocida } \\
\text { envuelta en hojas de la mazorca o de la misma planta de maíz, plátano, bijao, maguey, } \\
\text { aguacate o incluso papel aluminio o plástico. Pueden llevar o no relleno, el cual puede } \\
\text { contener carne, vegetales, chile, frutas, salsa, etc. Además pueden ser con sabor dulce o salado. } \\
\text { Es un platillo muy tradicional de la cocina mexicana. }\end{array}$ \\
\hline $\begin{array}{l}\text { Frijol con } \\
\text { puerco }\end{array}$ & $\begin{array}{l}\text { Una preparación tradicional de cada lunes en los hogares yucatecos es el frijol con puerco, } \\
\text { acompañado de deliciosas salsas de tomate, chile habanero y tortilla hechas a mano. }\end{array}$ \\
\hline $\begin{array}{l}\text { Frijoles } \\
\text { charros }\end{array}$ & $\begin{array}{l}\text { También conocidos como "frijoles a la charra", platillo que forma parte de la gastronomía } \\
\text { mexicana. Se prepara con frijoles guisados con cebolla, ajo, chile, tocino, salchichas y } \\
\text { chicharrón. Otros ingredientes comunes son tomates, cilantro, jamón, salsa, carne de cerdo } \\
\text { y chorizo. Se sirven calientes y tienen una consistencia semejante a una sopa. Son muy } \\
\text { sustanciosos para comerse como plato fuerte, por lo general sirven de guarnición o para } \\
\text { acompañar carnes asadas, arracheras, tacos al pastor. Es una preparación muy común en } \\
\text { la zona norte del país mexicano. Es importante señalar que se han incorporado alimentos } \\
\text { industrializados. }\end{array}$ \\
\hline Tacos al pastor & $\begin{array}{l}\text { Forman parte de la riqueza culinaria de México, tienen influencia libanés, se preparan con } \\
\text { carne de cerdo adobada, achiote, entre otras especies, la carne debe estar dorar o "quemar" } \\
\text { en un trompo. Una vez que la carne ya está en su punto, se coloca en una tortilla de maíz } \\
\text { pequeña, con la carne al pastor adobado, cilantro, cebolla y pina, se acompaña con una rica } \\
\text { salsa y limón que son el toque final del taco. }\end{array}$ \\
\hline Guayas & Fruto muy popular en la península de Yucatán. \\
\hline Empanadas & $\begin{array}{l}\text { Antojito mexicano que se realiza con maíz, se rellena de carne de pollo, de cerdo molida, con } \\
\text { queso, se fríe y se acompañar con lechuga, cebolla morada y salsa de chile habanero. }\end{array}$ \\
\hline Garnachas & $\begin{array}{l}\text { Antojito mexicano que consiste en una tortilla de maíz, con salsa roja, carne de res deshebrada } \\
\text { y cebolla picada, el cual se fríe. }\end{array}$ \\
\hline Sandwichón & $\begin{array}{l}\text { Preparación de la tradición yucateca, presenta una forma de pastel relleno de diversas } \\
\text { preparaciones que pueden ser dulces o saldas, o combinación de ambas, y es muy común en } \\
\text { las fiestas. }\end{array}$ \\
\hline Chicharrones & $\begin{array}{l}\text { Es una fritura regional considerada "alimento chatarra" rica en hidratos de carbono simple, } \\
\text { grasa saturada y sal, de gran contenido energético. }\end{array}$ \\
\hline
\end{tabular}

Elaboración propia

ambos grupos (sexo y comunidad). Por lo cual, no se pudo conocer en nivel de significancia en la diferencia de las frecuencias en ambos grupos, debido a que la muestra fue pequeña.

En el Cuadro 1 se presenta la definición de los términos de clasificación de alimentos industrializados.

El proyecto contó con la aprobación del Comité de Ética de la Dependencia y de la Institución Universitaria, lo cual permitió el desarrollo de éste. Los padres de familia o tutores de los jóvenes firmaron el consentimiento informado a través de reuniones escolares en donde se les explicó el motivo del estudio, así como el com- promiso de entregar los resultados de IMC. Aún con la autorización de los padres y tutores se les solicitó el asentimiento informado a los jóvenes para que pudieran participar libremente, quien no deseara hacerlo se le respetó su decisión, en todo momento se cuidó la confidencialidad de los datos de cada uno de los participantes.

\section{Resultados}

El estudio estuvo conformado por 292 estudiantes, de los cuales $51 \%$ fueron hombres y $49 \%$ mujeres. 
En cuanto a los resultados del IMC se encontró que el 58.2\% presenta un IMC dentro de la normalidad, $17.1 \%$ cursa con sobrepeso y el $24.3 \%$ obesidad; y solo el $0.30 \%$ bajo peso.

Respecto a la frecuencia de consumo de alimentos industrializados y modernos, se observa una frecuencia similar en el consumo de cereales; la tortilla $(100 \%)$, pan francés $(91 \%)$, arroz (77\%), pastas (69\%) y la masa (68\%) fueron los cereales (sin grasa) de mayor consumo, los cuales forman parte de la dieta diaria de la población yucateca. Respecto a cereales con grasa (industrializados e industrializados modernos) se observó una mayor variedad de alimentos de alto consumo, siendo el pan dulce (64\%) uno de ellos, seguido de manera consecutiva el cereal de caja $(62 \%)$, frituras $(57 \%)$, galletas ( $46 \%)$ y pan blanco (31\%) (Tabla 1). Los resultados se clasificaron según sexo y escuela (por comunidad), observándose un consumo similar entre hombres y mujeres en cuanto a los cereales con grasa.
La Tabla 2 presenta la frecuencia de consumo de alimentos industrializados de corte moderno de aceites y grasas, observándose una alta ingesta de aceite y mayonesa; es importante destacar la ingesta alta o moderada de manteca $(34 \%)$, tocino $(26 \%)$ y crema ( $45 \%)$; ya que presentan altos porcentajes de grasa saturada.

La frecuencia de azúcares, con y sin grasa, mostró un consumo alto y moderado en más del $50 \%$ de los adolescentes, salvo en los casos de mermelada y polvo para preparar aguas. El azúcar, refresco y chocolates fueron los alimentos de alto consumo (Tabla 3). Los alumnos en los grupos focales mencionaron consumir preparaciones con un alto contenido calórico, como hamburguesas, hot dog y pizza.

En cuanto a los resultados obtenidos en los grupos focales se describen cada uno de acuerdo a las categorías analizadas.

Tabla 1. Frecuencia de consumo de cereales (con y sin grasa) en los adolescentes de cada una de las secundarias del Mpio. de Abalá, Yucatán.

\begin{tabular}{|c|c|c|c|c|c|c|c|}
\hline \multirow[b]{2}{*}{ Alimento } & \multirow{2}{*}{$\begin{array}{c}\text { Toda la } \\
\text { población } \\
\text { n }(\%)\end{array}$} & \multicolumn{2}{|c|}{ Sexo } & \multicolumn{4}{|c|}{ Escuela } \\
\hline & & niño & niña & Abalá & Mucuyché & $\begin{array}{c}\text { Temozón } \\
\text { Sur }\end{array}$ & Uayalceh \\
\hline \multicolumn{8}{|l|}{ Tortilla ${ }^{a, x}$} \\
\hline Alto & $54(93)$ & $32(97)$ & $22(88)$ & $30(94)$ & $3(100)$ & $10(83)$ & 11 \\
\hline Moderado & $4(7)$ & $1(3)$ & $3(12)$ & $2(6)$ & - & $2(17)$ & $(100)$ \\
\hline Bajo & - & - & - & - & - & - & - \\
\hline No consumo & - & - & - & - & - & - & - \\
\hline \multicolumn{8}{|l|}{ Masa $^{a, \star}$} \\
\hline Alto & $6(10)$ & $3(9)$ & $3(12)$ & $3(10)$ & $3(100)$ & $3(25)$ & 11 \\
\hline Moderado & $33(58)$ & $18(56)$ & $15(60)$ & $13(42)$ & - & $6(50)$ & $(100)$ \\
\hline Bajo & $10(18)$ & $7(22)$ & $3(12)$ & $10(32)$ & - & - & - \\
\hline No consumo & $8(14)$ & $4(13)$ & $4(16)$ & $5(16)$ & - & $3(25)$ & - \\
\hline \multicolumn{8}{|l|}{ Pan francés ${ }^{a, \star}$} \\
\hline Alto & $44(76)$ & $24(73)$ & $20(80)$ & $24(75)$ & $1(33)$ & $1(100)$ & $7(63)$ \\
\hline Moderado & $9(15)$ & $7(21)$ & $2(8)$ & $6(19)$ & $1(33)$ & - & $2(18)$ \\
\hline Bajo & - & - & - & - & - & - & - \\
\hline No consumo & $5(9)$ & $2(6)$ & $3(12)$ & $2(6)$ & $1(34)$ & - & $2(19)$ \\
\hline \multicolumn{8}{|l|}{ Avena $^{a, *}$} \\
\hline Alto & $8(14)$ & $5(15)$ & $3(12)$ & $6(19)$ & $1(33)$ & $1(8)$ & - \\
\hline Moderado & $19(33)$ & $11(33)$ & $8(32)$ & $4(12)$ & $2(67)$ & $5(42)$ & $8(72)$ \\
\hline Bajo & $7(12)$ & $5(15)$ & $2(8)$ & $7(22)$ & - & - & - \\
\hline No consumo & $24(41)$ & $12(37)$ & $12(48)$ & $15(47)$ & - & $6(50)$ & $3(28)$ \\
\hline \multicolumn{8}{|l|}{ Cebada ${ }^{\star}$} \\
\hline Alto & $8(14)$ & $4(12)$ & $4(16)$ & $3(9)$ & $2(67)$ & $3(25)$ & - \\
\hline Moderado & $21(36)$ & $12(37)$ & $9(36)$ & $8(25)$ & - & $6(50)$ & $7(64)$ \\
\hline Bajo & $11(19)$ & $7(21)$ & $4(16)$ & $8(25)$ & - & - & $3(27)$ \\
\hline No consumo & $18(31)$ & $10(30)$ & $8(32)$ & $13(41)$ & $1(33)$ & $3(25)$ & $1(9)$ \\
\hline
\end{tabular}


Tabla 1. Frecuencia de consumo de cereales (con y sin grasa) en los adolescentes de cada una de las secundarias del Mpio. de Abalá, Yucatán.

\begin{tabular}{|c|c|c|c|c|c|c|c|}
\hline \multirow[b]{2}{*}{ Alimento } & \multirow{2}{*}{$\begin{array}{c}\text { Toda la } \\
\text { población } \\
\mathbf{n}(\%)\end{array}$} & \multicolumn{2}{|c|}{ Sexo } & \multicolumn{4}{|c|}{ Escuela } \\
\hline & & niño & niña & Abalá & Mucuyché & $\begin{array}{c}\text { Temozón } \\
\text { Sur }\end{array}$ & Uayalceh \\
\hline \multicolumn{8}{|l|}{$\operatorname{Arroz}^{\star}$} \\
\hline Alto & $20(34)$ & $12(36)$ & $8(32)$ & $11(34)$ & - & $5(42)$ & $4(36)$ \\
\hline Moderado & $25(43)$ & $13(40)$ & $12(48)$ & $13(41)$ & $3(100)$ & $6(50)$ & $3(27)$ \\
\hline Bajo & $9(16)$ & $5(15)$ & $4(16)$ & $5(16)$ & - & - & $4(37)$ \\
\hline No consumo & $4(7)$ & $3(9)$ & $1(4)$ & $3(9)$ & - & $1(8)$ & - \\
\hline \multicolumn{8}{|l|}{ Pastas $b, \star$} \\
\hline Alto & $16(28)$ & $8(24)$ & $8(32)$ & $8(25)$ & $1(33)$ & $5(41)$ & $2(18)$ \\
\hline Moderado & $24(41)$ & $14(43)$ & $10(40)$ & $13(40)$ & $1(33)$ & $3(25)$ & $7(63)$ \\
\hline Bajo & $5(9)$ & $3(9)$ & $2(8)$ & $5(16)$ & - & - & - \\
\hline No consumo & $13(22)$ & $8(24)$ & $5(20)$ & $6(19)$ & $1(34)$ & $4(34)$ & $2(19)$ \\
\hline \multicolumn{8}{|l|}{ Hot cakes ${ }^{b, *}$} \\
\hline Alto & $6(10)$ & $5(15)$ & $1(4)$ & $3(9)$ & $1(33)$ & $1(8)$ & $1(10)$ \\
\hline Moderado & $16(28)$ & $9(27)$ & $7(29)$ & $7(22)$ & $1(33)$ & $5(42)$ & $3(30)$ \\
\hline Bajo & $15(26)$ & $8(24)$ & $7(29)$ & $12(38)$ & - & $1(8)$ & $2(20)$ \\
\hline No consumo & $20(35)$ & $11(34)$ & $9(38)$ & $10(31)$ & $1(34)$ & $5(42)$ & $4(40)$ \\
\hline \multicolumn{8}{|l|}{ Galletas b,* } \\
\hline Alto & $9(15)$ & $3(9)$ & $6(24)$ & $2(6)$ & - & $5(42)$ & $2(18)$ \\
\hline Moderado & $18(31)$ & $11(33)$ & $7(28)$ & $8(25)$ & $2(67)$ & $4(33)$ & $4(36)$ \\
\hline Bajo & $5(9)$ & $3(9)$ & $2(8)$ & $4(13)$ & - & - & $1(9)$ \\
\hline No consumo & $26(45)$ & $16(49)$ & $10(40)$ & $18(56)$ & $1(33)$ & $3(25)$ & $4(37)$ \\
\hline \multicolumn{8}{|l|}{ Pan blanco ${ }^{b, *}$} \\
\hline Alto & $8(14)$ & $4(12)$ & $4(16)$ & $4(12)$ & $1(33)$ & $3(25)$ & - \\
\hline Moderado & $10(17)$ & $5(15)$ & $5(20)$ & $5(16)$ & - & $2(17)$ & $3(27)$ \\
\hline Bajo & $4(7)$ & $2(6)$ & $2(8)$ & $3(9)$ & - & - & $1(9)$ \\
\hline No consumo & $36(62)$ & $22(67)$ & $14(56)$ & $20(63)$ & $2(67)$ & $7(58)$ & $7(63)$ \\
\hline \multicolumn{8}{|l|}{ Cereal de caja ${ }^{b, \star}$} \\
\hline Alto & $17(29)$ & $6(18)$ & $11(44)$ & $5(16)$ & $1(33)$ & $6(50)$ & $5(45)$ \\
\hline Moderado & $19(33)$ & $12(37)$ & $7(28)$ & $10(31)$ & $1(33)$ & $5(42)$ & $3(27)$ \\
\hline Bajo & $8(14)$ & $5(15)$ & $3(12)$ & $8(25)$ & - & - & - \\
\hline No consumo & $14(24)$ & $10(30)$ & $4(16)$ & $9(28)$ & $1(34)$ & $1(8)$ & $3(28)$ \\
\hline \multicolumn{8}{|l|}{ Pan Dulce ${ }^{b, ¥}$} \\
\hline Alto & $15(26)$ & $7(21)$ & $8(32)$ & $6(19)$ & $1(33)$ & $5(42)$ & $3(27)$ \\
\hline Moderado & $22(38)$ & $11(34)$ & $11(44)$ & $11(34)$ & $2(67)$ & $6(50)$ & $3(27)$ \\
\hline Bajo & $6(10)$ & $5(15)$ & $1(4)$ & $6(19)$ & - & - & - \\
\hline No consumo & $15(26)$ & $10(30)$ & $5(20)$ & $9(28)$ & - & $1(8)$ & $4(46)$ \\
\hline \multicolumn{8}{|l|}{ Frituras $\stackrel{b, ¥}{ }$} \\
\hline Alto & $19(33)$ & $6(18)$ & $13(52)$ & $8(25)$ & $2(67)$ & $5(42)$ & $4(36)$ \\
\hline Moderado & $14(24)$ & $13(40)$ & $1(4)$ & $9(28)$ & - & $4(33)$ & $1(9)$ \\
\hline Bajo & $6(10)$ & $4(12)$ & $2(8)$ & $6(19)$ & - & - & - \\
\hline No consumo & $19(33)$ & $10(30)$ & $9(36)$ & $9(28)$ & $1(33)$ & $3(25)$ & $6(55)$ \\
\hline \multicolumn{8}{|l|}{ Sopa ${ }^{b, ¥}$} \\
\hline Alto & $5(9)$ & $2(6)$ & $3(12)$ & $2(6)$ & - & $2(17)$ & $1(9)$ \\
\hline Moderado & $13(22)$ & $8(24)$ & $5(20)$ & $3(9)$ & - & $4(33)$ & $6(55)$ \\
\hline Bajo & $6(10)$ & $5(15)$ & $1(4)$ & $5(16)$ & - & - & $1(9)$ \\
\hline No consumo & $34(59)$ & $18(55)$ & $16(64)$ & $22(69)$ & $3(100)$ & $6(50)$ & $3(27)$ \\
\hline \multicolumn{8}{|l|}{ Pastelillos ${ }^{\mathrm{b}, \mathrm{F}}$} \\
\hline Alto & $4(7)$ & $2(6)$ & $2(8)$ & - & - & $3(25)$ & $1(9)$ \\
\hline Moderado & $12(21)$ & $5(15)$ & $7(28)$ & $7(21)$ & $1(33)$ & $3(25)$ & $1(9)$ \\
\hline Bajo & $14(24)$ & $8(24)$ & $6(24)$ & $11(34)$ & $1(33)$ & $1(8)$ & $1(9)$ \\
\hline No consumo & $28(48)$ & $18(55)$ & $10(40)$ & $14(43)$ & $1(34)$ & $5(41)$ & $8(72)$ \\
\hline
\end{tabular}

${ }^{a}$ Parte de la dieta diaria, ${ }^{\mathrm{b}}$ Alimentos industrializados e industrializados modernos. ${ }^{*}$ cereales sin grasa, ${ }^{*}$ cereales con grasa.

Elaboración propia. 
Tabla 2. Frecuencia de consumo de aceites y grasas en los adolescentes de cada una de las secundarias del Mpio de Abalá, Yucatán.

\begin{tabular}{|c|c|c|c|c|c|c|c|}
\hline \multirow[b]{2}{*}{ Alimento } & \multirow{2}{*}{$\begin{array}{c}\text { Toda la } \\
\text { población } \\
\text { n }(\%)\end{array}$} & \multicolumn{2}{|c|}{ Sexo } & \multicolumn{4}{|c|}{ Escuela } \\
\hline & & niño & niña & Abalá & Mucuyché & $\begin{array}{c}\text { Temozón } \\
\text { Sur }\end{array}$ & Uayalceh \\
\hline \multicolumn{8}{|l|}{ Manteca } \\
\hline Alto & $6(10)$ & $3(9)$ & $3(12)$ & $4(12)$ & - & $1(8)$ & $1(9)$ \\
\hline Moderado & $14(24)$ & $9(27)$ & $5(20)$ & $8(25)$ & $1(33)$ & $4(33)$ & $1(9)$ \\
\hline Bajo & $6(11)$ & $4(12)$ & $2(8)$ & $4(12)$ & $1(33)$ & - & $1(9)$ \\
\hline No consumo & $32(55)$ & $17(51)$ & $15(60)$ & $16(51)$ & $1(34)$ & $7(59)$ & $8(73)$ \\
\hline \multicolumn{8}{|l|}{ Aceite $\mathrm{a}^{\star}$} \\
\hline Alto & $33(57)$ & $16(48)$ & $17(68)$ & $18(56)$ & $2(67)$ & $7(58)$ & $6(54)$ \\
\hline Moderado & $10(17)$ & $7(21)$ & $3(12)$ & $4(12)$ & $1(33)$ & $3(25)$ & $2(18)$ \\
\hline Bajo & $3(5)$ & $2(6)$ & $1(4)$ & $3(9)$ & - & - & - \\
\hline No consumo & $12(21)$ & $8(24)$ & $4(16)$ & $7(21)$ & - & $2(16)$ & $3(27)$ \\
\hline \multicolumn{8}{|l|}{ Mayonesa $\mathrm{a}^{\star}$} \\
\hline Alto & $17(37)$ & $8(35)$ & $9(39)$ & $8(40)$ & - & $7(58)$ & $2(18)$ \\
\hline Moderado & $17(37)$ & $11(48)$ & $6(26)$ & $6(30)$ & $2(67)$ & $3(25)$ & $6(54)$ \\
\hline Bajo & $3(6)$ & $2(8)$ & $1(4)$ & $1(5)$ & $1(33)$ & - & $1(9)$ \\
\hline No consumo & $9(20)$ & $2(9)$ & $7(31)$ & $5(25)$ & - & $2(16)$ & $2(18)$ \\
\hline \multicolumn{8}{|l|}{ Tocino $\mathrm{a}^{\star}$} \\
\hline Alto & $5(9)$ & $3(9)$ & $2(8)$ & $4(12)$ & - & - & $1(9)$ \\
\hline Moderado & $10(17)$ & $5(15)$ & $5(20)$ & $7(22)$ & $1(33)$ & $2(17)$ & - \\
\hline Bajo & $9(15)$ & $7(21)$ & $2(8)$ & $8(25)$ & - & - & $1(9)$ \\
\hline No consumo & $34(59)$ & $18(55)$ & $16(64)$ & $13(41)$ & $2(67)$ & $10(83)$ & $9(82)$ \\
\hline \multicolumn{8}{|l|}{ Crema $a^{*}$} \\
\hline Alto & $7(12)$ & $3(9)$ & $4(16)$ & $4(13)$ & $1(33)$ & $2(16)$ & - \\
\hline Moderado & $19(33)$ & $13(39)$ & $6(24)$ & $7(22)$ & $1(33)$ & $5(42)$ & $6(55)$ \\
\hline Bajo & $5(9)$ & $3(9)$ & $2(8)$ & $3(9)$ & - & - & $2(18)$ \\
\hline No consumo & $27(46)$ & $14(42)$ & $13(52)$ & $18(56)$ & $1(34)$ & $5(42)$ & $3(27)$ \\
\hline
\end{tabular}

$\mathrm{a}^{*}$ Alimento industrializado moderno

Elaboración propia.

Tabla 3. Frecuencia de consumo de azúcares en los adolescentes de cada una de las secundarias del Mpio de Abalá, Yucatán.

\begin{tabular}{|c|c|c|c|c|c|c|c|}
\hline \multirow[b]{2}{*}{ Alimento } & \multirow{2}{*}{$\begin{array}{c}\text { Toda la } \\
\text { población } \\
\mathbf{n}(\%)\end{array}$} & \multicolumn{2}{|c|}{ Sexo } & \multicolumn{4}{|c|}{ Escuela } \\
\hline & & Niño & niña & Abalá & Mucuyché & $\begin{array}{c}\text { Temozón } \\
\text { Sur }\end{array}$ & Uayalceh \\
\hline \multicolumn{8}{|l|}{ Azúcar * } \\
\hline Alto & $37(64)$ & $19(58)$ & $18(72)$ & $19(59)$ & $1(33)$ & $10(83)$ & $7(64)$ \\
\hline Moderado & $11(19)$ & $7(21)$ & $4(16)$ & $7(22)$ & $1(33)$ & $16(17)$ & $1(9)$ \\
\hline Bajo & $4(7)$ & $3(9)$ & $1(4)$ & $2(6)$ & - & - & $2(18)$ \\
\hline No consumo & $6(10)$ & $4(12)$ & $2(8)$ & $4(13)$ & $1(34)$ & - & $1(9)$ \\
\hline \multicolumn{8}{|l|}{ Gelatina *a } \\
\hline Alto & $9(16)$ & $6(18)$ & $3(12)$ & $2(6)$ & $1(33)$ & $5(42)$ & $1(9)$ \\
\hline Moderado & $28(48)$ & $13(40)$ & $15(60)$ & $13(40)$ & $1(33)$ & $5(42)$ & $9(82)$ \\
\hline Bajo & $14(24)$ & $10(30)$ & $4(16)$ & $13(41)$ & - & $1(8)$ & - \\
\hline No consumo & $7(12)$ & $4(12)$ & $3(12)$ & $4(12)$ & $1(34)$ & $1(8)$ & $1(9)$ \\
\hline \multicolumn{8}{|l|}{ Cátsup ${ }^{* a}$} \\
\hline Alto & $18(31)$ & $13(39)$ & $5(20)$ & $14(44)$ & - & $4(33)$ & - \\
\hline Moderado & $24(42)$ & $14(43)$ & $10(40)$ & $8(25)$ & $1(33)$ & $7(58)$ & $8(72)$ \\
\hline Bajo & $10(17)$ & $4(12)$ & $6(24)$ & $6(19)$ & $1(33)$ & - & $3(28)$ \\
\hline No consumo & $6(10)$ & $2(6)$ & $4(16)$ & $4(12)$ & $1(34)$ & $1(9)$ & - \\
\hline
\end{tabular}


Tabla 3. Frecuencia de consumo de azúcares en los adolescentes de cada una de las secundarias del Mpio de Abalá, Yucatán.

\begin{tabular}{|c|c|c|c|c|c|c|c|}
\hline \multirow[b]{2}{*}{ Alimento } & \multirow{2}{*}{$\begin{array}{c}\text { Toda la } \\
\text { población } \\
\text { n }(\%)\end{array}$} & \multicolumn{2}{|c|}{ Sexo } & \multicolumn{4}{|c|}{ Escuela } \\
\hline & & Niño & niña & Abalá & Mucuyché & $\begin{array}{c}\text { Temozón } \\
\text { Sur }\end{array}$ & Uayalceh \\
\hline \multicolumn{8}{|l|}{ Mermelada ${ }^{* a}$} \\
\hline Alto & $4(7)$ & $4(12)$ & - & $3(9)$ & - & - & $1(9)$ \\
\hline Moderado & $5(8)$ & $5(15)$ & - & $3(10)$ & $1(33)$ & $1(8)$ & - \\
\hline Bajo & $8(14)$ & $5(15)$ & $3(12)$ & $8(25)$ & - & - & - \\
\hline No consumo & $41(71)$ & $19(58)$ & $22(88)$ & $18(56)$ & $2(67)$ & $11(92)$ & $10(91)$ \\
\hline \multicolumn{8}{|l|}{ Dulce $^{*_{a}}$} \\
\hline Alto & $18(31)$ & $8(24)$ & $10(40)$ & $9(28)$ & $2(67)$ & $4(33)$ & $3(27)$ \\
\hline Moderado & $31(53)$ & $19(57)$ & $12(48)$ & $17(53)$ & $1(33)$ & $7(58)$ & $6(54)$ \\
\hline Bajo & $6(10)$ & $4(12)$ & $2(8)$ & $5(16)$ & - & $1(9)$ & - \\
\hline No consumo & $3(5)$ & $2(6)$ & $1(4)$ & $1(3)$ & - & - & $2(18)$ \\
\hline \multicolumn{8}{|l|}{ Refresco ${ }^{* a}$} \\
\hline Alto & $34(59)$ & $18(54)$ & $16(64)$ & $13(41)$ & $2(67)$ & $11(92)$ & $8(73)$ \\
\hline Moderado & $17(29)$ & $11(33)$ & $6(24)$ & $13(41)$ & $1(33)$ & $1(8)$ & $2(18)$ \\
\hline Bajo & $3(5)$ & $1(3)$ & $2(8)$ & $3(9)$ & - & - & - \\
\hline No consumo & $4(7)$ & $3(9)$ & $1(4)$ & $3(9)$ & - & - & $1(9)$ \\
\hline \multicolumn{8}{|l|}{ Jugo $^{* a}$} \\
\hline Alto & $16(28)$ & $7(21)$ & $9(36)$ & $5(16)$ & - & $8(67)$ & $3(27)$ \\
\hline Moderado & $21(36)$ & $12(37)$ & $9(36)$ & $11(34)$ & $2(67)$ & $3(25)$ & $5(46)$ \\
\hline Bajo & $8(14)$ & $5(15)$ & $3(12)$ & $7(22)$ & - & - & $1(9)$ \\
\hline No consumo & $13(22)$ & $9(27)$ & $4(16)$ & $9(28)$ & $1(33)$ & $1(8)$ & $2(18)$ \\
\hline \multicolumn{8}{|l|}{ Polvo (Jugo) ${ }^{{ }^{*} a}$} \\
\hline Alto & $11(19)$ & $5(15)$ & $6(24)$ & $7(22)$ & - & $3(25)$ & $1(9)$ \\
\hline Moderado & $16(28)$ & $7(21)$ & $9(36)$ & $7(22)$ & $1(33)$ & $5(42)$ & $3(27)$ \\
\hline Bajo & $2(3)$ & $2(6)$ & - & $1(3)$ & - & - & $1(9)$ \\
\hline No consumo & $29(50)$ & $19(57)$ & $10(40)$ & $17(53)$ & $4(67)$ & $4(33)$ & $6(55)$ \\
\hline \multicolumn{8}{|l|}{ Flan ${ }^{¥ \star a}$} \\
\hline Alto & $5(9)$ & $3(9)$ & $2(8)$ & $2(6)$ & - & $2(17)$ & $1(9)$ \\
\hline Moderado & $33(57)$ & $18(54)$ & $15(60)$ & $14(44)$ & $3(100)$ & $7(58)$ & $9(82)$ \\
\hline Bajo & $13(22)$ & $7(21)$ & $6(24)$ & $12(37)$ & - & - & $1(9)$ \\
\hline No consumo & $7(12)$ & $5(15)$ & $2(8)$ & $4(13)$ & - & $3(25)$ & - \\
\hline \multicolumn{8}{|l|}{ Galletas ${ }^{{ }^{* a}}$} \\
\hline Alto & $12(21)$ & $4(12)$ & $8(32)$ & $6(19)$ & $1(33)$ & $3(25)$ & $2(18)$ \\
\hline Moderado & $20(34)$ & $12(36)$ & $8(32)$ & $10(31)$ & $1(33)$ & $5(42)$ & $4(36)$ \\
\hline Bajo & $5(9)$ & $2(6)$ & $3(12)$ & $4(12)$ & - & - & $1(9)$ \\
\hline No consumo & $21(36)$ & $15(46)$ & $6(24)$ & $12(38)$ & $1(34)$ & $4(33)$ & $4(37)$ \\
\hline \multicolumn{8}{|l|}{ Chocolate } \\
\hline Alto & $28(48)$ & $14(43)$ & $14(56)$ & $13(41)$ & $2(67)$ & $8(67)$ & $5(46)$ \\
\hline Moderado & $14(24)$ & $10(30)$ & $4(16)$ & $8(25)$ & $1(33)$ & $4(33)$ & $1(9)$ \\
\hline Bajo & $4(7)$ & $2(6)$ & $2(8)$ & $2(6)$ & - & - & $2(18)$ \\
\hline No consumo & $12(21)$ & $7(21)$ & $5(20)$ & $9(28)$ & - & - & $3(27)$ \\
\hline \multicolumn{8}{|l|}{ Helado ${ }^{\mp \neq a}$} \\
\hline Alto & $14(24)$ & $6(18)$ & $8(32)$ & $8(25)$ & - & $4(33)$ & $2(18)$ \\
\hline Moderado & $25(43)$ & $15(46)$ & $10(40)$ & $9(28)$ & $2(67)$ & $6(50)$ & $8(73)$ \\
\hline Bajo & $6(10)$ & $4(12)$ & $2(8)$ & $5(16)$ & - & $1(8)$ & - \\
\hline No consumo & $13(23)$ & $8(24)$ & $5(20)$ & $10(31)$ & $1(33)$ & $1(9)$ & $1(9)$ \\
\hline
\end{tabular}




\section{Tiempos de comida}

\section{Consumo de alimentos industrializados en el desayuno}

El desayuno es el tiempo de comida más importante del día, ya que permite proporcionar los nutrimentos y la energía necesaria para llevar a cabo las actividades del día, y en los adolescentes es aún más importante, ya que durante la jordana escolar les permite estar atentos a las clases escolares $^{27}$.

Los estudiantes mencionaron que el desayuno que consumen está conformado por una serie de platillos y alimentos que caen en la clasificación de industrializados modernos en su mayoría, como lo es: cereal de caja, yogurt, hot cakes, salchichas, galletas, pan dulce, sopa nissin ${ }^{\circledR}$, etc. Entre las preparaciones de mayor consumo en el desayuno (Cuadro 2) destaca el huevo con salchicha, huevo con frijol y tortilla, café con leche, burritas (Cuadro 1), etc. Tal y como se puede observar en los siguientes comentarios realizados por los estudiantes de la secundaria de Abalá: “... desayunamos huevo... jajajajaja, chocomilk, café con leche, burritas y lo que prepare mi mamá..." "también huevo con frijol... a mí huevo con salchicha, tortillas... también hot cakes, estos me gustan mucho, son de mis favoritos, pero no siempre los hace mi mamá". Se nota una mezcla de alimentos modernos y tradicionales que en la actualidad están permeando la dieta de las comunidades mayas del estado y que en los jóvenes se está transformando aún más. Cuando se les cuestionó por qué consumen estos alimentos mencionaron "... porque esto nos prepara mi mamá”... “yo luego le digo que me haga burritas (Cuadro 1) o hot cakes porque siempre me da huevo...", se puede notar que sus gustos y preferencias están supeditados a lo que la madre de familia decida preparar de desayuno para sus hijos y muchas veces la economía familiar deja de lado lo que realmente el adolescente desea comer.

Los alimentos que mencionan consumir los adolescentes en el desayuno son similares, se observan preparaciones tradicionales que incorporan alimentos modernos, por ejemplo, huevos con salchicha, lo que está llevando a la alimentación a un proceso de transculturación de la dieta, que incluye alimentos hipercalóricos y que están influyendo en los altos niveles de sobrepeso y obesidad, encontrados en los jóvenes. En el Cuadro 2 se observan los alimentos y las preparaciones que consumen.

Llama la atención que la escuela que presenta una mayor variedad de consumo de preparacio- nes es la que se localiza en Abalá, cabecera municipal, al parecer las otras dos presentan un desayuno poco variado y monótono, de acuerdo a lo comentado por los estudiantes.

Según el $\mathrm{CONAPO}^{20}$ señala al municipio como de alta marginación, por lo cual, las localidades que lo conforman presentan mayor pobreza que la cabecera municipal que es la localidad de Abalá, además la cabecera municipal cuenta con una| mayor disponibilidad de alimentos industrializados de corte moderno.

\section{Consumo de alimentos industrializados en el receso escolar}

El receso escolar es un momento para el descanso, convivencia, juego, así como la oportunidad de comer alguna colación que se prepara en casa y que los jóvenes llevan a la escuela o se compren alimentos que la escuela. Durante este tiempo de comida los adolescentes mencionaron que los alimentos que más les gusta comer son las frituras, por lo que el recreo es el momento esperado por los estudiantes para comprar alimentos con alto contenido calórico tal y como se observa en el Cuadro 2, también pueden adquirir algunas de las preparaciones de corte moderno que se ofrecen como las hamburguesas o los "perros calientes", lo que indica que la escuela contribuye en cierta manera a se fomentar el consumo de una dieta hipercalórica en los estudiantes.

Además, los alumnos mencionan que no cuentan con suficiente dinero para comprar alimentos de otro tipo, es decir, la escuela no ofrece alimentos saludables y si los ofreciera es probable que los jóvenes no pudieran adquirirlos por elevado costo que podrían tener, es importante mencionar que identifican que este tipo de productos son alimentos chatarra, que son malos para la salud y que además engordan y producen enfermedades como la diabetes, se les cuestionó que por qué los consumen, a lo que ellos respondieron: porque nos gustan, porque son baratos y fáciles de comprar y además quitan el hambre, se puede observar que tienen un conocimiento de lo que son estos productos y de lo que pueden ocasionar, pero aun así son consumidos frecuentemente.

\section{Alimentos consumidos en el almuerzo y cena}

El almuerzo está conformado prácticamente por preparaciones propias de la región y que aún son parte de esa tradición y riqueza culinaria de las comunidades rurales indígenas mayas, entre ellos destacan los salbutes, puchero, cochinita (Cuadro 1), etc., como se observa en el Cuadro 2. 
Cuadro 2. Consumo de alimentos de acuerdo a su preparación y momento en los adolescentes por escuela en el Mpio. de Abala, Yucatán.

\begin{tabular}{|c|c|c|c|c|c|}
\hline \multirow{2}{*}{$\begin{array}{c}\text { Escuelas } \\
\text { Secundarias } \\
\text { (localidad) }\end{array}$} & \multicolumn{5}{|c|}{ Consumo de alimentos } \\
\hline & En el desayuno & En el almuerzo & En la cena & Con sus amigos & En la escuela \\
\hline $\begin{array}{l}\text { Secundaria } \\
\text { "Daniel Ayala } \\
\text { Pérez". } \\
\text { (Cabecera } \\
\text { municipal de } \\
\text { Abalá) }\end{array}$ & $\begin{array}{l}\text { “... comemos } \\
\text { de desayuno } \\
\text { cereal con leche, } \\
\text { pan con leche, } \\
\text { huevo con frijol } \\
\text { y tortillas, huevo } \\
\text { con salchicha, } \\
\text { café con leche, } \\
\text { pan y galletas, } \\
\text { burritas, sopa } \\
\text { nissin, yogurth, } \\
\text { hot cakes, torta } \\
\text { de jamón y } \\
\text { queso, torta } \\
\text { de pollo, carne } \\
\text { puerco de } \\
\text { ayer, licuado } \\
\text { de frutas"... } \\
\text { "además yo me } \\
\text { levantó tarde } \\
\text { y desayuno lo } \\
\text { que mi mamá } \\
\text { preparó de } \\
\text { comer, ya no } \\
\text { desayuno". } \\
\text { (Participación } \\
\text { de los } \\
\text { estudiantes de } \\
\text { los tres grados de } \\
\text { la escuela). }\end{array}$ & $\begin{array}{l}\text { “...la comida es lo } \\
\text { más rico de la casa, } \\
\text { me gusta cuando } \\
\text { mi mamá prepara } \\
\text { empanizado es lo } \\
\text { que más me gusta, } \\
\text { hace también sopa } \\
\text { de fideos o de letras, } \\
\text { puchero, ¡mmmmm!, } \\
\text { pollo asado, tortitas } \\
\text { asado, cochinita } \\
\text { ¡mmmm! Eso casi } \\
\text { no hace y cuando } \\
\text { hace no queda nada } \\
\text { en la casa, también } \\
\text { comemos el frijol con } \\
\text { puerco y también nos } \\
\text { comemos la comida } \\
\text { del día anterior, } \\
\text { comemos poc chuc, } \\
\text { pero esto la verdad } \\
\text { no siempre, lentejas, } \\
\text { chilaquiles, bistec, } \\
\text { carne asada, chuletas, } \\
\text { frijoles charros, } \\
\text { chiles rellenos, } \\
\text { espagueti... ya nos } \\
\text { dio hambre de tanto } \\
\text { hablar de comida } \\
\text { ijajajajajaja!”. } \\
\text { (Participación de los } \\
\text { estudiantes de los tres } \\
\text { grados de la escuela). }\end{array}$ & $\begin{array}{l}\text { “...comemos } \\
\text { tortas, salchichas } \\
\text { fritas o como } \\
\text { las venden, nos } \\
\text { gustan mucho, } \\
\text { 'perros calientes', } \\
\text { tamal, Hot } \\
\text { Cakes, cereal con } \\
\text { leche, panuchos, } \\
\text { caso con leche, } \\
\text { hamburguesas, } \\
\text { resto del } \\
\text { almuerzo, huevo } \\
\text { con frijol, huevo } \\
\text { con salchicha, } \\
\text { burritas, } \\
\text { sándwiches, } \\
\text { huevo, pan } \\
\text { con café, eso } \\
\text { cenamos...”. } \\
\text { (Participación de } \\
\text { los estudiantes de } \\
\text { los tres grados de } \\
\text { la escuela). }\end{array}$ & $\begin{array}{l}\text { “....cuando estamos } \\
\text { con nuestros amigos } \\
\text { comemos charritos, } \\
\text { Sabritas, Pepsi, } \\
\text { chocolates, helados, } \\
\text { marquesitas ;mmm!... } \\
\text { ricas, papas a la } \\
\text { francesa, sopa Nissin }{ }^{\circledR}, \\
\text { pizza, chicharrón } \\
\text { preparado, tacos } \\
\text { al pastor, nachos, } \\
\text { hamburguesas.... Ah! } \\
\text { también nos gustar } \\
\text { comer los mangos y las } \\
\text { guayas cuando hay” } \\
\text { y sus papás les da el } \\
\text { dinero para comprar "si } \\
\text { nuestros papá o nuestras } \\
\text { mamás... yo le pido a } \\
\text { mi abuelita jajajaja y } \\
\text { me da más dinero que } \\
\text { mis papás" y solo comen } \\
\text { esos alimentos, "los } \\
\text { domingos nos dan más } \\
\text { dinero y acá en el pueblo } \\
\text { vende, hamburguesas, } \\
\text { pizza y 'perros calientes' } \\
\text { compramos eso”. } \\
\text { (Participación de los } \\
\text { estudiantes de los tres } \\
\text { grados de la escuela). }\end{array}$ & $\begin{array}{l}\text { “... en la escuela comemos } \\
\text { lo que venden, y lo que } \\
\text { vende pueden ser tortas } \\
\text { de carne asada, tamales, } \\
\text { hamburguesas, espagueti, } \\
\text { sopa nissin }{ }^{\circledR}, \text { panuchos, } \\
\text { perros calientes (hot- } \\
\text { dog), sandwichón, sufflé, } \\
\text { garnachas, tacos, arroz con } \\
\text { leche, empanadas, también } \\
\text { comemos Sabritas y galletas, } \\
\text {...tomamos agua simple, } \\
\text { agua de tamarindo, agua de } \\
\text { horchata, agua de jamaica, } \\
\text { jugos azucarados (friolin }{ }^{\circledR} \text { ), } \\
\text { algunas veces Coca-Cola }{ }^{\circledR} . . \\
\text { Esos alimentos que comemos } \\
\text { no nos gustan, porque } \\
\text { no tienen sabor, por eso } \\
\text { compramos las sabritas }{ }^{\circledR} y \\
\text { galletas”. “¿Y eso alimentos } \\
\text { que consumen en la escuela } \\
\text { son bueno? No, porque } \\
\text { tienen muchas calorías, } \\
\text { tienen muchas grasas } \\
\text { saturadas y condimentos... } \\
\text { Entonces, ¿por qué compran } \\
\text { esos alimentos? porque } \\
\text { no hay nada más...” } \\
\text { (participación los estudiantes } \\
\text { de los tres grados escolares) }\end{array}$ \\
\hline
\end{tabular}

Aunque en la cena los adolescentes mencionaron algunos alimentos y preparaciones correspondientes a las modernas como las hamburguesas, "perros calientes" (hot dog); se notó que esta situación es más común en la cabecera municipal que en las demás localidades, también es habitual que en las comunidades rurales se acostumbre cenar lo que se preparó de la comida. En el Cuadro 2 se pueden observar las preparaciones alimentarias que forman parte de la tradición mexicana y de las poblaciones rurales e indígenas mayas como los panuchos y los tamales (Cuadro 1).

Es importante señalar que los estudiantes participantes en el grupo focal comentaron que la comida o el almuerzo (como se le conoce en las comunidades estudiadas) siempre se acompaña con refresco embotellado, mencionando lo siguiente: la comida no sabe igual si no hay un refresco en la mesa (comentario de los participantes en el grupo focal de la escuela secundaria de Abalá, Yucatán), también fue interesante encontrar expresiones ya le dije a mis papás que no compren refresco pero no nos hacen caso (comentario de los participantes en el grupo focal de la escuela secundaria de Uayalceh, Yucatán).

Se puede notar que las preparaciones que forman parte de la comida son aún tradicionales, pudiera destacarse como preparación moderna 
Cuadro 2. Consumo de alimentos de acuerdo a su preparación y momento del consumo en los adolescentes por escuela en el Mpio. de Abala, Yucatán.

\begin{tabular}{|c|c|c|c|c|c|}
\hline \multirow{2}{*}{$\begin{array}{c}\text { Escuelas } \\
\text { Secundarias } \\
\text { (localidad) }\end{array}$} & \multicolumn{5}{|c|}{ Consumo de alimentos } \\
\hline & En el desayuno & En el almuerzo & En la cena & Con sus amigos & En la escuela \\
\hline $\begin{array}{l}\text { Telesecundaria } \\
\text { "Cuauhtémoc". } \\
\text { (Temozón Sur) }\end{array}$ & $\begin{array}{l}\text { “...jmmmm! } \\
\text { (pensando la } \\
\text { respuesta)... } \\
\text { café con galletas, } \\
\text { torta de pan } \\
\text { francés, pan con } \\
\text { leche, cereal con } \\
\text { leche... siempre } \\
\text { es lo mismo...”. } \\
\text { (participación } \\
\text { de los } \\
\text { estudiantes de } \\
\text { los tres grados de } \\
\text { la escuela) }\end{array}$ & $\begin{array}{l}\text { “...Casi siempre } \\
\text { comemos lo mismo... } \\
\text { desayunamos huevo, } \\
\text { comemos huevo } \\
\text { con frijol... algunas } \\
\text { veces comemos } \\
\text { pollo, también se } \\
\text { hace la sopa de } \\
\text { verduras, sopas } \\
\text { de pasta, lentejas, } \\
\text { frijol con tortilla } \\
\text { o arroz, huevo, } \\
\text { tortilla de máquina”. } \\
\text { (Participación de los } \\
\text { estudiantes de los tres } \\
\text { grados de la escuela). }\end{array}$ & $\begin{array}{l}\text { “...cuando hay } \\
\text { cereal en la casa } \\
\text { cenamos cereal } \\
\text { con leche, huevo } \\
\text { con jamón o con } \\
\text { salchicha, huevo } \\
\text { con pan, burritas, } \\
\text { tortas de jamón } \\
\text { y queso, perros } \\
\text { calientes cuando } \\
\text { los venden o } \\
\text { luego mi mamá } \\
\text { prepara, el resto } \\
\text { de la comida, que } \\
\text { eso casi siempre } \\
\text { comemos, eso no } \\
\text { me gusta, cuando } \\
\text { sobra la comida } \\
\text { y la tenemos que } \\
\text { comer otra vez... } \\
\text { ”. (Participación } \\
\text { de los estudiantes } \\
\text { de los tres grados } \\
\text { de la escuela). }\end{array}$ & $\begin{array}{l}\text { “...Lo que más nos } \\
\text { gusta comer son las } \\
\text { Sabritas, ah! también } \\
\text { los chocolates, los } \\
\text { charritos... mangos, } \\
\text { huaya con chilito piquín } \\
\text { ¡mmmm... sabe bien } \\
\text { bueno!, galletas también, } \\
\text { palomitas, Coca- } \\
\text { Cola }{ }^{\circledR} \text { y si no tenemos } \\
\text { mucho dinero también } \\
\text { tomamos jugos de } \\
\text { bolsita” y solo compran } \\
\text { esos alimentos, "pues } \\
\text { sí, acá en el pueblo no } \\
\text { venden otras cosas, } \\
\text { luego se antojan las } \\
\text { hamburguesas o los } \\
\text { perros calientes... pero } \\
\text { no los venden comemos } \\
\text { eso” (participación de } \\
\text { los estudiantes de los tres } \\
\text { grados de la escuela). }\end{array}$ & $\begin{array}{l}\text { “...tortas de pan francés } \\
\text { con jamón o carne asada, } \\
\text { empanadas, quesadillas, } \\
\text { panuchos, chicharrones } \\
\text { (frituras), Sabritas }{ }^{\circledR} \\
\text { y tomamos refrescos } \\
\text { embotellados como Coca- } \\
\text { Cola }{ }^{\circledR}, \text { jugos azucarados } \\
\text { (friolín }{ }^{\circledR} \text { ), agua de } \\
\text { horchata... eso es todo lo } \\
\text { que venden en la escuela, } \\
\text { luego nuestras mamás nos } \\
\text { traen de comer porque hay } \\
\text { días que no venden nada... y } \\
\text { qué les preparan sus mamás, } \\
\text { nos traen empanadas, } \\
\text { sándwiches, tortas, panuchos, } \\
\text { eso casi siempre...” } \\
\text { (participación de los } \\
\text { estudiantes de los tres grados } \\
\text { de la escuela). }\end{array}$ \\
\hline $\begin{array}{l}\text { Secundaria } \\
\text { "Eligio Ancona } \\
\text { Rosado". } \\
\text { (Uayalceh) }\end{array}$ & $\begin{array}{l}\text { “... cereal con } \\
\text { leche, galletas } \\
\text { con café, } \\
\text { quesadillas, } \\
\text { tortas"... } \\
\text { "siempre } \\
\text { comemos } \\
\text { lo mismo, } \\
\text { no siempre } \\
\text { nuestros papás } \\
\text { tienen dinero } \\
\text { para preparar } \\
\text { algo rico de } \\
\text { desayuno, } \\
\text { siempre } \\
\text { comemos huevo } \\
\text { con frijoles". } \\
\text { (Participación } \\
\text { de los } \\
\text { estudiantes de } \\
\text { los tres grados de } \\
\text { la escuela). }\end{array}$ & $\begin{array}{l}\text { “...comemos } \\
\text { cochinita, frijol con } \\
\text { puerco casi siempre } \\
\text { la verdad cuando } \\
\text { se come siempre } \\
\text { ya no nos gusta, se } \\
\text { fastidia uno de comer } \\
\text { siempre eso, comemos } \\
\text { tamales, espagueti, } \\
\text { eso sí inos gusta y } \\
\text { mucho! ensalada } \\
\text { de zanahoria o } \\
\text { papas... immmmm! } \\
\text { Nos gusta imucho!”. } \\
\text { (Participación de los } \\
\text { estudiantes de los tres } \\
\text { grados de la escuela). }\end{array}$ & $\begin{array}{l}\text { "Siempre } \\
\text { cenamos el resto } \\
\text { de la comida, } \\
\text { cuando hay } \\
\text { dinero comemos } \\
\text { cereal con leche, } \\
\text { galletas con café, } \\
\text { quesadillas, solo } \\
\text { eso siempre..." } \\
\text { (Participación de } \\
\text { los estudiantes de } \\
\text { los tres grados de } \\
\text { la escuela). }\end{array}$ & $\begin{array}{l}\text { “... silencio y risas, } \\
\text { ijajajaja! ... comemos } \\
\text { mangos, botanas } \\
\text { como los charritos, } \\
\text { el chicharrón, los } \\
\text { churritos...cuando } \\
\text { tenemos dinero nos gusta } \\
\text { comprar las Sabritas }{ }^{\circledR}, \\
\text { Chetos }{ }^{\circledR}, \text { Fritos }{ }^{\circledR} . . . \\
\text { tomamos Coca-Cola } \\
\text { Pepsi-Cola }{ }^{\circledR} \text { y cuando } \\
\text { no tenemos dinero } \\
\text { compramos juguitos, } \\
\text { y acá en el pueblo } \\
\text { casi no venden nada } \\
\text { y no tenemos dinero, } \\
\text { si queremos comprar } \\
\text { hamburguesas tenemos } \\
\text { que ir a Abalá y allá } \\
\text { no nos dan permiso” } \\
\text { (participación de los } \\
\text { estudiantes de los tres } \\
\text { grados de la escuela). }\end{array}$ & 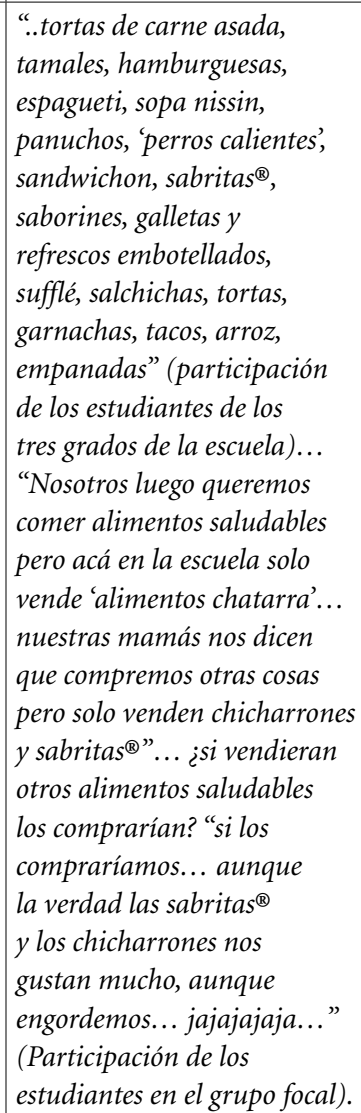 \\
\hline
\end{tabular}


al espagueti, porque de acuerdo a lo mencionado por los jóvenes, las preparaciones que consumen en la actualidad aun forman parte de la rica y exquisita comida yucateca, lo cual, representa un valor importante en épocas recientes, ya que la comida moderna está desplazando éste tipo de preparaciones. No se debe perder de vista que el desayuno es rico en alimentos modernos industrializados al igual que el receso escolar, lo que representa un cambio en la alimentación en los estudiantes.

\section{Alimentos que consumen los adolescentes con sus amigos}

El esparcimiento y el convivio con los amigos en esta etapa de la vida es de suma importancia, ya que les permite elegir sus propios alimentos y actividades que realizarán, en este caso los alimentos que los adolescentes prefieren consumir cuando se encuentran con sus amigos son los hipercalóricos o los conocidos como alimentos chatarra (Cuadro 2), la razón que los lleva a elegir estos productos se debe al sabor que tienen, tal y como lo mencionan en el siguiente texto: ...nos gustan porque ¡saben bien ricos!, no es lo mismo comer fideos que comer Sabritas ${ }^{\circledR}$ o los Fritos ${ }^{\circledR}$... ah! y sí tomamos Coca Cola $^{\circledR}$, ¡sabe más rico!...también nos gustan muchos los chicharrones preparados (Expresiones de los participantes de la escuela secundaria de Mucuyché), mencionaron que estos alimentos son de fácil acceso, son fáciles de comprar, por eso los comemos (comentario expresado por estudiantes de la escuela secundaria de Abalá). Aunque también expresaron consumir frutas de temporada acompañadas con chile molido.

Se puede observar que los alimentos que prefieren los adolescentes cuando conviven con sus amigos se inclinan hacia los productos industrializados modernos, es decir, botanas de alto valor calórico ricos en carbohidratos simples, azúcares y conservadores, así como también, prefieren elegir bebidas azucaradas, entre ellos los refrescos de cola y jugos embotellados.

Es importante destacar que los jóvenes tienen el deseo de comer otro tipo de alimentos, como las hamburguesas, no las consumen debido principalmente a la falta de dinero y disponibilidad en la localidad en donde viven, tal y como se refleja en los comentarios, en la cabecera municipal, se encuentra un mayor acceso a este tipo de productos.

\section{Alimentos preferidos por los adolescentes para consumo}

Este apartado se divide en dos categorías: alimentos o preparaciones tradicionales preferidas y alimentos industrializados modernos preferidos.

En cuanto a las preparaciones tradicionales preferidas por los jóvenes, éstos mencionaron que los alimentos que más les gusta comer son la cochinita pibil, frijol con puerco (Cuadro 1); aunque también mencionaron consumir preparaciones de estilo moderno como el espagueti verde, empanizado, entre otros.

Respecto a los alimentos industrializados de mayor preferencia son las frituras, preparaciones como la hamburguesa, "perros calientes" (hot dog) y los tacos al pastor, además de las frituras. Los adolescentes mencionaron que el consumir este tipo de alimento chatarra (comentarios expresados por los estudiantes de todos los grupos focales realizados) no es bueno para la salud ya que ocasiona obesidad, y que además produce enfermedades como hipertensión, diabetes, entre otras (comentarios expresados por los estudiantes de todos los grupos focales realizados), se les preguntó por qué lo comían y mencionaron nos gusta.

Las preparaciones tradicionales son de su agrado, pero depende de la disponibilidad de la madre de familia para realizarlas, así como del acceso económico.

Los resultados muestran que los adolescentes de las escuelas estudiadas presentan un consumo de alimentos tradicionales como es la tortilla (Cuadro 1), el frijol, el azúcar, aceite que son consumidos de manera frecuente y generalizada, así como preparaciones tradicionales que conforman su alimentación, pero con la inclusión de alimentos industrializados modernos que se consumen también de manera frecuente, uno de ellos son las bebidas azucaradas y que están transformando la alimentación de los adolescentes de éstas localidades, lo que deja al descubierto una transición alimentaria de corte más urbano, menos nutritiva, hipercalórica, rica en grasas saturadas, azúcares, sal y con un contenido alto de aditivos, lo que está llevando a la población adolescente a presentar altos porcentaje de sobrepeso y obesidad.

Los adolescentes de la cabecera municipal (Abalá) presentan una alimentación más variada y con un mayor consumo de alimentos industrializados modernos debido a la mayor disponibili- 
dad de ellos, de acuerdo a lo comentado en los grupos focales aunque llama la atención que en la frecuencia de consumo de alimentos esto no se refleja, lo cual puede deberse al número de personas que respondieron la encuesta.

\section{Percepción del consumo de alimentos industrializados}

En cuanto a la percepción de este tipo de productos los jóvenes mencionaron que son "limentos chatarra", que "no son buenos para la salud, debido a que tienen muchas calorías, si se comen en exceso, 'hacen que subas de peso'... y tienen muchas grasas saturadas... que pueden causar enfermedades como diabetes, colesterol, triglicéridos... (Participación de los estudiantes de las secundarias de Abalá). Los adolescentes de la escuela secundaria de Temozón Sur y Uayalceh comentaron ... son comida chatarra, tienen grasas, además de que hacen daño al cuerpo... son malos, se observa en las respuestas que los adolescentes tienen conocimiento de los daños que pueden tener estos productos a la salud, pero aun así no son conscientes de eso, probablemente porque son jóvenes ya que mencionaron que las enfermedades crónicas solo las padecen las personas adultas como sus abuelos y tal vez sus papás.

Se les cuestionó del por qué las consumían y mencionaron que por su sabor, porque están "baratas" y que son fácil de comprar.

Valdría la pena profundizar en estos temas con los adolescentes de secundarias rurales e indígenas, debido a que son escasos los estudios en estas poblaciones, además que los productos industrializados que consumen tienen un gran impacto en la salud de los jóvenes de estas comunidades.

\section{Discusión}

Existe una escasez de literatura referente a la percepción y al consumo de alimentos en adolescentes de un medio rural e indígena, especialmente en la región de la península de Yucatán, los pocos estudios que se realizan son enfocados a la alimentación de niños preescolares o escolares del medio urbano, por lo cual, la discusión se limita y alguna de las investigaciones realizadas están enfocadas a los adultos. Sin embargo, los resultados encontrados son valiosos debido a que se pudo detectar un elevado consumo de alimentos llamados "chatarra", aunque es importante mencionar que se consumen preparaciones tradicionales lo que indica que las comunidades se en- cuentran en una etapa de transición alimentaria, tal y como lo reporta Guerrero ${ }^{28}$ donde señala que los nuevos hábitos de alimentación adquiridos impactan a la población con la selección de productos alimentarios modernos que dejan un costo en la salud de la población, principalmente aquella de bajos recursos económicos.

Los alimentos industrializados de corte moderno (muchos de ellos) como los refrescos embotellado, los jugos, galletas, botanas dan la pauta para percatarse que forman parte del consumo frecuente en los adolescentes de estas comunidades, por lo que su alimentación está conformada por alimentos hipercalóricos, debido al alto contenido de hidratos de carbono simple o azúcares, así como de grasas saturadas, conservadores y aditivos, tal y como lo reporta en un estudio Aguirre et al. ${ }^{29}$, en donde encontraron un alto consumo de galletas y jugos. En otro estudio realizado por González-Castell et al..$^{30}$ en población preescolar detectaron un consumo elevado de jugos y refrescos embotellados, cuyos resultados son consistentes con los encontrados en este estudio; esto puede estar contribuyendo al alto porcentaje de sobrepeso y obesidad en los adolescentes de cada una de las escuelas secundarias de las comunidades, lo que en un futuro cercano serán propensos a desarrollar enfermedades crónicas degenerativa, tal y como lo señala la ENSANUT, 2012 $2^{14}$, reportando que los adolescentes de comunidades rurales mayas presentan altos índices de sobrepeso y obesidad.

Se observó una dieta diversificada que incluye preparaciones con alimentos modernos, aunque aún permanecen patrones de consumo de alimentos que forman parte de la dieta tradicional como lo es el huevo, el frijol y la tortilla, entre otros. Estos resultados coinciden con los realizados en población adulta de comunidades mayas yucatecas ${ }^{7,31}$.

Los adolescentes cuando se encuentran conviviendo con los amigos eligen alimentos industrializados modernos y prefieren preparaciones de corte moderno como pueden ser las hamburguesas, lo que contribuye a la generación de nuevos hábitos alimentarios, influidos por presiones sociales, por modas alimentarias, por gustos y por preferencias del grupo de amigos, es decir, se toman decisiones en conjunto, lo que influye negativamente en ellos.

El estudio visualiza que la modernización de la dieta se asocia al abandono de ricas y sabias tradiciones alimentarias de las comunidades mayas yucatecas, a favor de la elección y adopción de un modelo occidental de consumo, rico en 
alimentos industrializados que suele tener mayor impacto en la población adolescente, lo cual representa un alto costo en la salud y economía ${ }^{14,32}$

Los testimonios expresados por los adolescentes coinciden con Contreras ${ }^{33}$, quien menciona que las decisiones para la elección de los alimentos se basan en el significado que les otorgan, dejando a un lado los contenidos nutricionales o las necesidades biológicas, como se nota en los resultados obtenidos. También coinciden con lo que Santacoloma y Quiroga ${ }^{34}$ afirman en su estudio, las conductas alimentarias están motivadas por diversos propósitos, tal cual fue señalado por los adolescentes cuando conviven con sus amigos, los alimentos que eligen son diferentes a los que consumen a la hora de la comida en su hogar, es decir, está condicionada la alimentación por el entorno social, la convivencia, los gustos, así como también para saciar el hambre, el grupo al que pertenezcan va a ejercer una influencia directa en el tipo de alimentos que se consumen, no solo con adolescentes que viven en contextos urbanos, sino también en rurales e indígenas de México.

Los resultados evidencian que la elección del consumo de alimentos industrializados modernos hipercalóricos en los estudiantes está marcada por la alta disponibilidad de éstos, tanto, en los espacios escolares como en cada una de las localidades que habitan. El gusto, el sabor, pero principalmente el bajo costo de los productos facilita su adquisición, además de que "quitan el hambre", no se debe perder de vista que la población estudiada presenta condiciones de pobreza, lo que hace vulnerable a los jóvenes a presentar sobrepeso y obesidad.

Existe una mezcla de patrones de alimentación, tanto tradicionales como modernos (transculturación alimentaria), una gran parte los platillos preferidos por los estudiantes fueron las preparaciones tradicionales, aunque también existe un elevado consumo de alimentos industrializados como lo son los refrescos embotellados, los jugos azucarados, las galletas, botanas, etc., que forman parte de la dieta diaria, que desafortunadamente ha permeado las localidades rurales e indígenas de Yucatán.

Los jóvenes tienen conocimiento que el consumo de los "alimentos chatarra" generan sobrepeso y obesidad, así como algunas enfermedades crónicas degenerativas como la diabetes y la hipertensión, lo que indica que la política de salud debe reorientarse, no solo en informar a los jóvenes el impacto de estos productos en la salud, sino a la toma de decisiones sobre la importancia de evitar enfermedades crónicas a edades tempranas con el fin de mejorar las calidad de vida e impulsar el seguir consumiendo preparaciones y alimentos tradicionales saludables propios de las comunidades mayas yucatecas de México.

\section{Colaboraciones}

O Pérez-Izquierdo participó en el diseño, estructura del artículo, redacción del mismo y en la interpretación de la información cuati-cualitativa; J Perera-Ríos en el análisis de los datos cualitativos y en la estadística descriptiva; S Cárdenas-García en la redacción final; I Aranda-González en los análisis de los datos y en el diseño metodológico; y MR Castillo-Barradas en la recolección de datos en campo.

\section{Agradecimiento}

A las autoridades de cada una de las escuelas participantes, así como a cada uno de los profesores que permitieron se llevara a cabo el estudio. Así como a los padres de familia por autorizar el permiso.

\section{Referencias}

1. De Garine I. Anthropologie de L'alimentation et pluridisciplinarite. Ecol Hum 1988; 9(2):21-40.

2. Pérez SE, Vega A, Romero G. El proceso alimentario y la división sexual del trabajo doméstico. El caso de una comunidad rural mexicana. Cuaderno Espacio $\mathrm{Fe}$ menino 2008; 20(2):99-130.

3. Villagómez P. Entre lo que se debe y lo que se puede: Percepción y satisfacción de las necesidades alimentarias en la Ciudad de México. Acta sociológica 2016; (70):99-128.

4. Pineda S, Aliño M. El concepto de adolescencia. In: Márquez R, Colás EF, editores. Manual de Prácticas Clínicas para la atención integral a la Salud en la Adolescencia. $2^{\mathrm{a}}$ ed. Ciudad de la Habana: MINSAP; 2002. p. 15-23.

5. Macedo G, Bernal M, López P, Hunot C, Vizmanos B, Rovillé F. Hábitos alimentarios en adolescentes de la Zona Urbana de Guadalajara, México. Antropo 2008; (16):29-41. [acceso 2018 Mar 3]. Disponible en: http://www.didac.ehu.es/antropo/16/16-5/MacedoOjeda.pdf 
6. Kant AK. Consumption of energy-dense, nutrient poor foods by adult Americans: nutritional and health implications. The Third National Health and Nutrition Examination Survey 1988-1994. Am J Clin Nutr 2000; 72(4):929-36.

7. Pérez-Izquierdo O, Nazar A, Salvatierra B, Pérez-Gil S, Rodríguez L, Castillo Burguete MT, Mariaca Mendez R. Frecuencia del consumo de alimentos industrializados modernos en la dieta habitual de comunidades mayas de Yucatán, México. Estudios Sociales. 2012; 20(39):155-184.

8. Fishler C. El (h)omnívoro. El gusto, la cocina y el cuerpo. Barcelona: Anagrama; 1995.

9. Reyes I, Nazar A, Estrada E, Mundo V. Alimentación y suficiencia energética en indígenas migrantes de los altos de Chiapas, México. Archivos Latinoamericanos de Nutrición 2007; 57(2):155-162.

10. Messer E. Globalización y dieta. In: Beltrán M, Arroyo P, editores. Antropología y Nutrición. México: Fundación Mexicana para la Salud (Funsalud), Fondo Nestlé para la Nutrición; 2006.

11. Fondo de las Naciones Unidas para la Infancia (Unicef). Los derechos de la infancia y la adolescencia en México. [En Línea]. México: Unicef; 2018. [acceso 2018 Mar 3]. Disponible en: http://www.unicef.org/ mexico/spanish/SITAN-UNICEF2018.pdf

12. Rivera JA, Barquera S, González-Cossío T, Olaiz G, Sepúlveda J. Nutrition transition in Mexico and in other Latin American countries. Nutr Rev 2004; 62(7):149157.

13. Olaiz G, Rivera J, Shamah T, Rojas R, Villalpando S, Hernández M, Sepúlveda-Amor J. Encuesta Nacional de Salud y Nutrición. Cuernavaca: Instituto Nacional de Salud Pública. 2006.

14. Gutiérrez JP, Rivera J, Shamah T, Oropeza C, Hernádez M. Encuesta Nacional de Salud y Nutrición 2012 (ENSANUT, 2012). Resultados Nacionales. Cuernavaca: Instituto Nacional de Salud Pública; 2012.

15. Echeverri C. Percepciones de los adolescentes frente a las influencias psicosociales que inciden en sus hábitos alimentarios. Revista Virtual Universidad Católica del Norte [En línea]. 2015; (45):181-195. [acceso 2018 Mar 3]. Disponible en: http://revistavirtual.ucn.edu. co/index.php/RevistaUCN/article/viewFile/666/1197

16. Romero A, Pérez-Gil S, Rosa S. Cuerpo y percepción en una zona rural de México: ¿una preocupación solo de mujeres o también de hombres? Demetra 2017; 12(1):21-40.

17. Oseguera D. Comidas peligrosas: la percepción social de la (in)seguridad alimentaria. Estudios sobre las culturas contemporáneas 2004; 10(19):31-51.

18. Vargas LM. Sobre el concepto de percepción. Alteridades 1994; 4(8):47-53.

19. Contreras J, Gracia M. Alimentación y cultura. Perspectivas antropológicas. Barcelona: Ariel; 2005.

20. Consejo Nacional de Población (Conapo). Índice de marginación por localidad 2010. México: Conapo; 2012.

21. Consejo Nacional de Evaluación de la Política de Desarrollo Social (Coneval). Medición de la pobreza, Yucatán, 2010-2015. [En Línea]. Coneval; 2015. [acceso en 2018 Dic 6]. Disponible en: https://www.coneval. org.mx/coordinacion/entidades/Yucatan/Paginas/pobreza_municipal2015.aspx
22. Instituto Nacional de Estatística e Geografia (INEGI). Inventario Nacional de Vivienda 2016. [En Línea]. 2016 [acceso en 2018 Dic 6]. Disponible en: http:/ www.beta.inegi.org.mx/app/mapa/INV/Default.aspx

23. Organización Mundial de la Salud (OMS). Patrones de crecimiento infantiles. [En Línea]. Ginebra: OMS; 2018. [acceso en 2018 Mayo 15]. Disponible en: http://www.who.int/childgrowth/standards/imc_ para_edad/es/

24. Pérez AB, Marván L. Sistema Mexicano de Alimentos Equivalentes. 2a ed. México: Fomento de Nutrición y Salud A.C.; 2006.

25. Franco K, Valdés E. Frecuencia de consumo de alimentos, índice de masa corporal y porcentaje de grasa en estudiantes universitarios: un estudio longitudinal. Ciencia UAT 2013; 7(2):18-22.

26. Ruiz O. Metodología de la investigación cualitativa. Bilbao: Universidad de Deusto; 2012.

27. Delbino C. Conocimientos, actitudes y prácticas alimentarias en adolescentes concurrentes al colegio F.A.S.T.A. [tesis]. Fasta: Universidad de FASTA; 2013

28. Guerrero AC. Transculturación alimentaria en Venezuela y su influencia en el desarrollo de obesidad. Revista Electrónica de Psicología Política [En Línea]. 2017; 15(38):89-98. [acceso en 2018 Mayo 15]. Disponible en: http://www.psicopol.unsl.edu.ar/2017-Julio-Articulo\%2006.pdf

29. Aguirre J, Escobar M, Chávez A. Evaluación de los parones alimentarios y la nutrición en cuatro comunidades rurales. Salud Pública de México 1988; 40(5):398-407.

30. González-Castell, González-Cossío T, Rivera JA. Alimentos industrializados en la dieta de los preescolares mexicanos. Salud Pública de México 2007; 49(5):345356.

31. Pérez-Izquierdo O. Cambios en la alimentación de dos comunidades mayas del estado de Yucatán. Elementos para una política integral de educación nutricional [tesis]. Campeche: ECOSUR; 2011.

32. Ortega RM, Andrés PA, Requejo AM, López-Sobaler AM, Redondo RM, González-Fernández M. Hábitos alimentarios e ingesta de energía y nutrientes en adolescentes con sobrepeso en comparación en comparación con los de peso normal. Ann Esp 1996; 44(3):203208.

33. Contreras J. La obesidad: una perspectiva sociocultural. Zainac 2005; (27):31-52.

34. Santacoloma AM, Quiroga LA. Perspectiva de estudio de la conducta alimentaria. Revista Iberoamericana de Psicología: Ciencia y Tecnología 2009; 2(2):7-15

Artículo presentado en 26/06/2018

Aprobado en 15/04/2019

Versión final presentada en 17/04/2019 